\title{
Coal-Quality Information-Key to the Efficient and Environmentally Sound Use of Coal
}

\section{Coal Quality}

The rock that we refer to as coal is derived principally from decomposed organic matter (plants) consisting primarily of the element carbon. When coal is burned, it produces energy in the form of heat, which is used to power machines such as steam engines or to drive turbines that produce electricity. Almost 60 percent of the electricity produced in the United States is derived from coal combustion.

Coal is an extraordinarily complex material. In addition to organic matter, coal contains water (up to 40 or more percent by weight for some lignitic coals), oils, gases (such as methane), waxes (used to make shoe polish), and perhaps most importantly, inorganic matter (fig. 1). The inorganic matter-minerals and trace elements - cause many of the health, environmental, and technological problems attributed to coal use (fig. 2).

"Coal quality" is the term used to refer to the properties and characteristics of coal that influence its behavior and use. Among the coal-quality characteristics that will be important for future coal use are the concentrations, distribution, and forms of the many elements contained in the coal that we intend to burn.

Knowledge of these quality characteristics in U.S. coal deposits may allow us to use this essential energy resource more efficiently and effectively and with less undesirable environmental impact.

\section{Coal-Quality Data Base}

The U.S. Geological Survey (USGS) maintains COALQUAL, the largest data base containing coal quality information on U.S. coal. This data base is available as a USGS open-file report (Bragg, L.J., Oman, J.K., Tewalt, S.J., Oman, C.J., Rega, N.H., Washington, P.M., and Finkelman, R.B., 1997, National Coal Resources Data System-U.S. coal quality database: U.S. Geological Survey Open-File Report 97-134, available on the World Wide Web at URL http://energy.er.usgs.gov/products/ databases/coalqual/intro.htm). Information from this data base can be used to locate

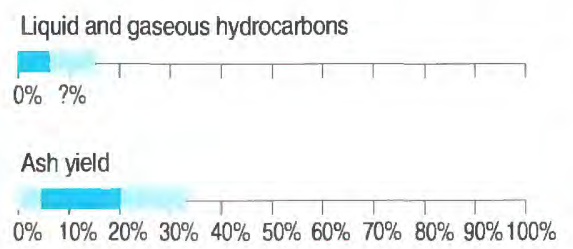

coal samples having quality characteristics desirable for technological use and environmental compatibility (fig. 3).

\section{Solid organic matter \\ $0 \% \quad 10 \% \quad 20 \% \quad 30 \% \quad 40 \% \quad 50 \% \quad 60 \% \quad 70 \% \quad 80 \% \quad 90 \% 100 \%$ \\ Moisture content \\ $0 \% \quad 10 \% 20 \% 30 \% \quad 40 \% \quad 50 \% \quad 60 \% \quad 70 \% \quad 80 \% 90 \% 100 \%$}

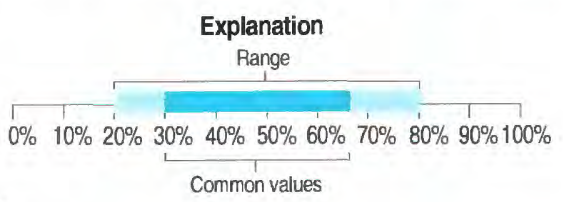

Figure 1. Composition of coal.

\section{COMPONENTS \\ IMPACTS}

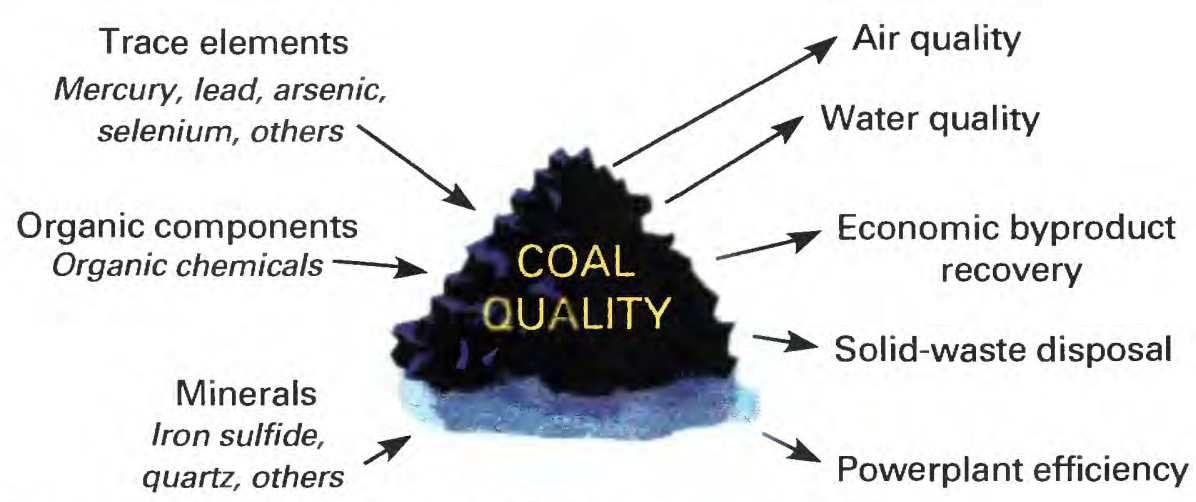

Figure 2. Examples of coal-quality components and their potential impacts on society.

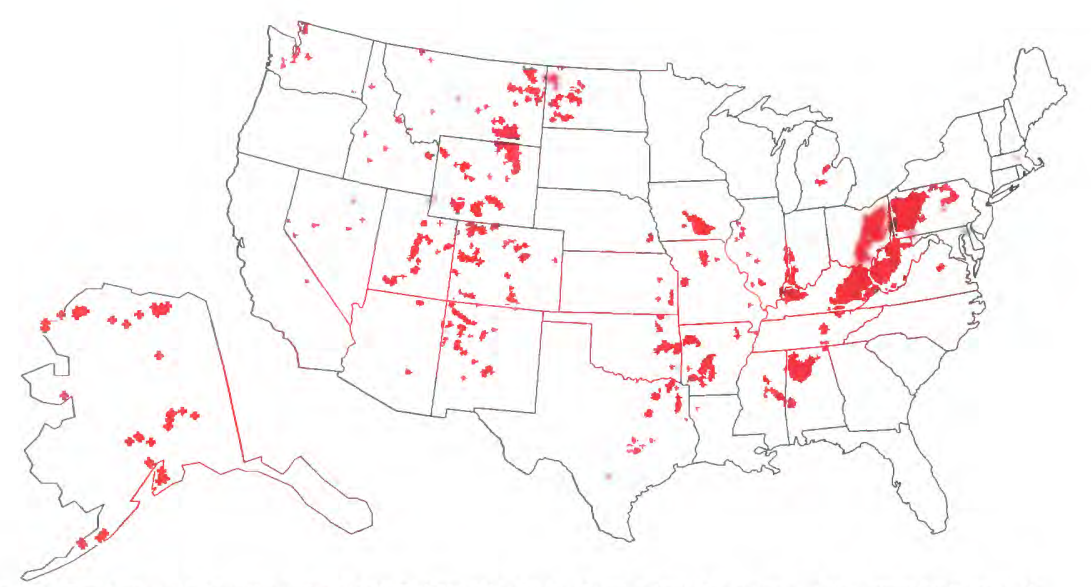

Figure 3. Coal sample locations from USCHEM (the U.S. Geological Survey geochemical data base), July 1994. USCHEM is part of the USGS National Coal Resources Data System. COALQUAL is a subset of USCHEM. 
The USGS is also conducting research on the modes of occurrence (chemical form) of key elements in coal. The resulting information may be used to anticipate the behavior of these elements during mining, cleaning, combustion, weathering, and so on. For example, USGS research indicates that mercury and arsenic occurring in coal are found primarily in pyrite (fig. 4); chromium is largely in illite, a clay mineral, and cadmium is found in sphalerite, a zinc sulfide mineral.

\section{Value of Coal-Quality Information}

\section{Coal Chemistry}

Coal-burning utilities can mitigate the effects of coal combustion at three stages in the combustion process. Coal can be cleaned before it is burned, a process called beneficiation, but this tends to remove useful organic compounds along with undesirable trace elements.

Modification of combustion conditions can also reduce the amount of undesirable combustion products, but only a small fraction of the total is removed when compared to beneficiation or the scrubbing of effluents. Scrubbing or washing the effluent, or using electrostatic precipitators or "baghouses" to capture ash particles, removes many chemicals before they enter the environment. Knowledge of coal chemistry is important to determine which mitigation procedure will be most efficient in reducing the amount of hazardous material emitted by a powerplant.

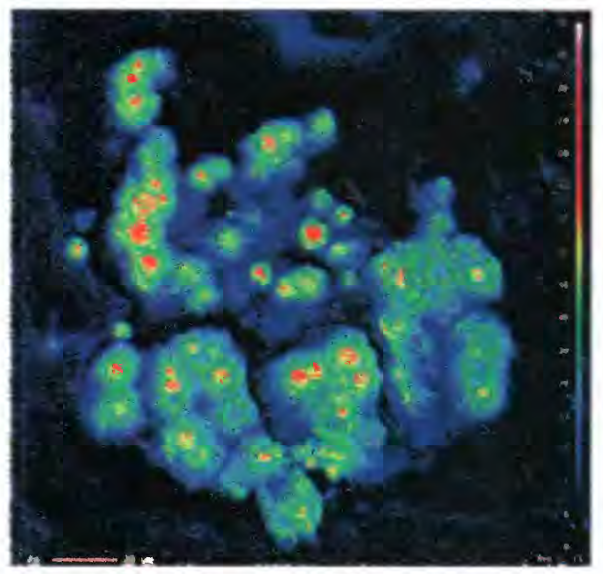

Figure 4. Photomicrograph showing distribution of arsenic in pyrite from a bituminous coal. The red, yellow, and green indicate elevated levels of arsenic; blue indicates background concentrations. Bar in lower left corner is 20 microns.
Removing selenium prior to combustion in order to minimize selenium in a powerplant's emissions may not be costeffective or even feasible. Recently completed studies show that selenium is enriched during the precombustion cleaning process because most of the element is organically bound. In similar studies, USGS research indicates that removal of lead can be complex. Lead always occurs as galena, the sulfide of lead; galena is found in coal in a variety of ways. Precombustion cleaning removes a large proportion of galena in fracture fillings but not galena that is distributed as micron-sized particles dispersed throughout the organic matrix. In this case, postcombustion removal of lead and sulfur is required. The knowledge of how an element is bound and how it is distributed in coal can help utility managers make proper pollution-control decisions.

\section{Environmental Impact}

Determining the mode of occurrence of metals and other chemicals in coal is key to the ability to predict how different coals will respond to the latest technology and uses. For example. selenium in trace amounts (about 1 part per million, or ppm) occurs in at least six different forms in coal from the Powder River basin in Wyoming. Coal scientists, including USGS workers, have determined that the form of selenium (selenium-bearing pyrite) most likely to create water pollution accounts for only 10 percent of the total selenium. Certain coals in the Gulf Coast region contain about $5 \mathrm{ppm}$ selenium, but environmental problems attributed to the trace element are minimal because the amount of rainfall received in this area is sufficient to flush selenium from the soil and to dilute it in water bodies. By contrast, insufficient rainfall in Wyoming and Montana, where coals contain less than $1 \mathrm{ppm}$ selenium, allows animals and plants to take up and retain selenium in harmful quantities. Therefore, the popular belief that the greater the quantity of an undesirable element, the worse the environment will suffer, can be incorrect. Knowing the form of the element in coal and how it will behave during coal cleaning and combustion are essential for cost-effective environmental protection.
Engineers are concerned with the amount of sodium in coal because sodium contributes to the fouling of heat exchanger pipes - a multimillion-dollar problem. The ash from Wasatch coals of Utah contains as much as 15 percent sodium, or 5 times normal levels; consequently, energy companies have avoided these coals. USGS research indicates that the sodium is bound in a fracture-filling zeolite mineral that can be removed easily prior to combustion. The remaining sodium is organically bound and falls within normal engineering limits. Prior to these studies, energy companies did not know how sodium and other chemicals occurred in coals.

\section{Use of Coal Waste Products}

This country produces more byproducts from coal extraction and use than from any nonenergy product except sand and gravel, and limestone. Only 30 percent of coal byproducts are used, primarily in the construction industry, while nearly 70 million tons are disposed of. Much of this waste contains potentially hazardous chemicals, such as trace metals, but the waste also contains significant quantities of valuable metals. These products are generally considered to be nonhazardous when disposed of properly. If coal byproducts were recycled for the metals that they contain (such as copper. nickel, cadmium, mercury, and silver), the amount of hazardous trace metals being dispersed in the environment would be reduced and the United States would be less dependent on foreign sources of these metals. The concept of using the entire resource instead of only a portion of it is both economically and environmentally sound.

Coal-quality research provides a bridge to the energy future by allowing us to achieve efficient, cost-effective, and environmentally sound use of coalone of our most valuable resources.

\section{For more information, contact:}

\section{Robert B. Finkelman}

U.S. Geological Survey

National Center, MS 956

Reston, VA 20192

Telephone: (703) 648-6412

E-mail: rbf@usgs.gov 